\title{
Reflexiones sobre Rothko: el inventor de la televisión en color
}

\author{
amparo Serrano de Haro *
}

Si para algunos críticos la Historia del Arte moderno es parecida a un striptease (en el que la pintura, a partir del Romanticismo, se va despojando una a una de sus ropas de academia clasicista poniendo un énfasis - que se traduce en istmo- en la prenda que se quita y luego arroja al suelo) al desconcertado visitante de una colección de cuadros contemporáneos no puede dejarle de parecer que el arte es una sucesión de fórmulas plásticas para lograr el éxito: la caligrafía febril de Pollock, los lienzos terrosos de Tapies, o la extraña luminosidad cuadrangular de Rothko.

Digo bien, el auténtico espectador, no aquel que mientras el crítico es un voyeur y el pintor se mancha las manos practica el voyeurismo de sí mismo. En ese sentido, nunca se hablará lo bastante de la necesidad de poner espejos en galerías y museos que gratifiquen instantaneamente al visitante con su propia imagen de personal culta, acelerando así su recorrido.

Este espectador auténtico, dotado de sentido común e interés por el arte, se encuentra frente a los lienzos de Rothko como delante de misteriosas catedrales de color. Sin la voz de Greenberg, sin antecedentes ni sucesores, estos cuadros llenan las paredes como decoración, para los entendidos, mística.

Pero tomemos esa apreciación de "fórmula" al pie de la letra; al fin y al cabo no es inadecuado, cuando el mismo Rothko junto con Gotlieb hace un Ilamamiento público a los pintores norteamericanos, en una carta de 1943 al New York Times, instándolos a que «inventen" una nueva temática del arte que sea universalmente atractiva e intemporal, explicando que se trata de lograr una expresión simple del pensamiento complejo. Esto fue en 1943, ya estaba cerca de lograr la fórmula que en 1947 le convertiría en Rothko. (Anteriormente a esto, como todo el mundo sabe, él era sólo un pintor ruso exiliado desde la temprana edad de 10 años

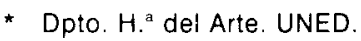


en EE.UU. navegando entre los distintos estilos que la gran marejada intelectual procedente de Europa iba trayendo en sucesivas oleadas. Luego dicen que las guerras no sirven para nada). Su fórmula consiste en una estructura de preferencia cuadrangular (la pantalla) que se inserta junto con otra u otras más pequeñas (los mandos) en la gran estructura que forma el lienzo. La clave está en que inevitablemente esperamos ver aparecer algo en la pantlla, y en un movimiento hipnótico vamos repetidamente del gran lienzo (la televisión) a la forma cuadrangular (la pantalla) hasta casi estar en un trance... esperando... esperando y topándonos, una y otra vez, obligatoriamente con la materialidad del color. Hasta que comprendemos que finalmente estamos viendo algo. Algo que sin duda, presentado de otra forma, habríamos despreciado antes de llegar a verlo. Estamos viendo rojo o azul o amarillo o rosa o naranja o negro. $Y$, como todo psiquiatra sabe, "ver un color" es algo mucho más que simplemente eso. Es entrar en todo un estado de ánimo. De esta forma sencilla y paradójica a la materialidad más brutal va asociada la espiritualidad más exquisita, a lo simple lo complejo. Es un mensaje que podría ser, como pretendió Rothko, universal, si se dedica un poco de tiempo a cada cuadro y si no se dejan en la puerta los parámetros habituales de juicio. Entre ellos, el tan despreciado sentido común que se suele reemplazar, en estas ocasiones, por un bagaje de prejuicios, que tanto si son positivos como si son negativos, sólo sirven para estorbar. Pero no nos pongamos nerviosos y analicemos despacio la fórmula compuesta esencialmente de dos elementos: estructura y color.

Desde el Renacimiento impera la noción del cuadro como una ventana; ventana sobre cuyo alfeizar (o marco) apoyados podíamos ver incidentes bíblicos, poderosos personajes, delicias mitológicas, apetitosas viandas... Las vanguardias que tanto rompieron, no se atrevieron con el marco ${ }^{1}$ a pesar de que empezaron a vislumbrar allí la última de las trampas. Sin duda los dadaístas lo eludieron, pero sus bromas no bastaron para hacerle desaparecer. Cezanne y los cubistas fueron los primeros que vieron que la mejor forma de destruir el marco era darle un empleo y lo establecieron como un coordinado de diseño y dibujo que todo lo controlaba, lo que si bien permitía perder definitivamente la mentira de la tridimensionalidad sin que el cuadro se les cayera dio lugar al hábito restrictivo de ser el marco de referencia obvia de cada línea y cada pincelada. Pero los únicos que supieron convertir esa ventana en puerta, por así decirlo, fueron los expresionistas abstractos norteamericanos también Ilamados la «Escuela

Al hablar de marco no me refiero solamente al borde de madera u otro marial en el que se encuadra la pintura sino al mismo borde del lienzo. 
de Nueva York». Esto lo consiguieron de tres maneras, dos de ellas son en referencia a la estructura del cuadro y la tercera es la utilización que hicieron del color. Al entrar en el análisis estructural dejaremos la palabra a Clement Greenberg que fue el teórico de esta generación americana y quizá el primer crítico de arte contemporáneo que ha existido. Greenberg dice en su artículo de finales de los años cincuenta, "Pintura tipo norteamericano" ${ }^{2}$ :

"Rothko y Newman se han negado a emprender el camino de la geometría cubista (...). Han preferido elegir su camino, en lugar de verse empujados a él; y al elegirlo, han decidido escapar de la geometría a través de la propia geometría. Sus líneas rectas no son un eco de las del marco sino una parodia. El cuadro se hace todo el marco en si mismo. (...) Aquí se destruye la noción cubista e inmemorial, del borde del cuadro como confín; (...) el borde del cuadro se repite en el interior y hace el cuadro, en lugar de servirle meramente de eco. Los bordes limitadores de los lienzos mayores (...) ahora lo descubrimos, actúan justamente igual que las líneas interiores: dividen pero no separan, ni encierran, ni atan; delimitan pero no limitan. Las pinturas no se fusionan con el espacio circundante; preservan - cuando aciertan-su integridad y unidad propias. Pero tampoco están alli, en el espacio, como objetos aislados y solos; en suma apenas si son cuadros de caballete, y justamente por ello, han escapado a las asociaciones de "objeto" (y objeto de lujo) que han ido cada vez más aparejadas al cuadro de caballete. Las pinturas de Newman (y Rothko) exigen al fin, el calificativo de campos".

Esta utilización de la geometría va a ir unida a lo que es el segundo elemento estructural anteriormente señalado: un cambio de dimensión en el tamaño del cuadro, que se hace más grande. Según Greenberg ${ }^{3}$ :

"Hasta la segunda mitad de los años cuarenta en Nueva York no se descubrió el modo de situarse en una superficie tan extensa que sus confines quedaban fuera (o eran meramente periféricos) del campo de visión del artista mientras éste trabajaba. De esta manera el pintor fue capaz de llegar al março como "resultado" en lugar de someterse a él como algo dado de antemano".

Este desprecio por la composición clásica, la superación del formato tradicional, y la desaparición de imágenes icónicas en favor de la superficie misma del cuadro va a dar lugar a una noción de espacialidad, creándose lo que algunos Ilamarán pintura ambiental.

2 Greenberg, Clement, "Arte y Cultura", Gustavo Gili 1979, pág. 206. Aunque esencialmente en este artículo se refiere al pintor Barnett Newman no hay duda de que sus comentarios pueden aplicarse, también, a Rothko.

Opus Cit., pág. 200 
El lugar que ocupa el color en este tipo de pintura es esencial y nada de lo explicado anteriormente referente a la estructura puede ser entendido o puede haber existido sin la evolución que experimenta el color en la historia del siglo xx. Sin duda, es el protagonismo que alcanza el color lo que determina que puedan aparecer estruturas con las características anteriormente explicadas. El color puro que utiliza Rothko y que aceptamos con naturalidad hoy en día, es el resultado de una sucesiva serie de descubrimientos y renuncias. A ese respecto hay muchos distintos caminos y muchos distintos pintores que podemos considerar en la base del color de Rothko. Nosotros nos centraremos en un personaje que llega a Nueva York en 1940 para quedarse allí hasta su muerte en 1944: Piet Mondrian, y en su primera obra teórica: "La nueva imagen de la pintura».

Mondrian ejerció una influencia decisiva sobre toda la generación americana del expresionismo abstracto en diversos aspectos, pero nosotros vamos a centrarnos en el menos estudiado, el factor del color, donde la riqueza de las teorías sobrepasa lo que fue su utilización en la práctica pictórica. Hay una circunstancia además que considero importante resaltar, cuando Mondrian escribe "La nueva imagen de la pintura" entre los años 1917-1918 está totalmente bajo la influencia del teósofo M.H.J. Schoenmaekers; esto quizá sirva para sostener la validez de la impresión mística que mucha gente atribuye a los cuadros de Rothko. Para Mondrian en esta nueva «imagen" que él propugna son necesarios en cuanto al color una serie de condiciones de las que he entresacado las que me parecen más en relación con la obra de Rothko, con la obviedad de que Rothko no se limita solamente a los colores primarios.

En primer lugar:

"Hacer concreto un color quiere decir: primero, decantar el color natural a color primario; segundo, reducir el color a puro; y, tercero, cerrar el color de tal manera que aparezca como unidad de planos rectangulares." (...) «Porque el color actúa como una forma pura, plana y cerrada, la nueva imagen llega a ser imagen directa de extensión, es decir, imagen directa de lo que causa la apariencia del espacio" ${ }^{4}$.

En segundo lugar:

«El color natural de la nueva imagen no sólo se profundizó porque se decantara a color primario sino también porque apareció de forma plana.

4 Mondrian, Piet, "La nueva imaen en la pintura". Murcia 1983, pág. 33. 
La contemplación habitual no ve plano el color en la naturaleza: ve las cosas (el color) como corporeidad, como curvatura" ${ }^{5}$.

En tercer lugar:

"Hacer el color realmente universal, se realiza en la nueva imagen no sólo por medio de buscar lo universal en el color como color mismo, sino también por llevar los colores entre sí a una unidad por relación equilibrada. Así, desaparece lo particular de cada color en sí: así, la relación domina el color" ${ }^{6}$.

Finalmente:

«En la pintura real-abstracta, el color primario aparece, por lo tanto, muy relativamente, lo principal es que el color esté libre de lo individual y de sensaciones individuales y que sólo manifieste la emoción silenciosa de lo universal. Los colores ya no expresan lo natural, sin embargo, siguen siendo reales" ?.

De estos puntos se pueden sacar diversas conclusiones. Me gustaría destacar en primer lugar cómo se nos narra el proceso de abstracción del color para insertarse en esta nueva imagen y en segundo lugar la tendencia a símbolo universal que sustenta este arte. Universal que no está opuesto a individual (aunque en Mondrian sí lo parezca) sino que es como un paso más, es la superación de lo individual, no su aniquilamiento. Buena prueba de ello es toda la serie de cuadros que pinta Rothko a partir de 1969, e inclusive antes, presa ya de la depresión que le llevará al suicidio un año más tarde. Son grandes oleos en negro, gris, blanco y negro. La televisión en color se ha averiado, gravemente. No hay nada más patéticamente autobiográfico que esos grandes cuadros desnudos de ilusión, no hay nada más claro, más universalmente explícito. Como dice Simón Marchán refiriéndose a este tipo de pintura:

"Su sentidc último es la experiencia sensible del color y las asociaciones posibles se vinculan a la constitución psíquica de cada individuo pudiendo desencadenar una cadena de asociaciones privadas intensas ${ }^{8}$.

Antes de terminar querría señalar lo ingenuo que sería atribuir a Rothko la paternidad de la televisión en color ya que éste, como todos los grandes

Opus Cit., pág. 37.

Opus Cit, pág. 35.

Opus Cit. pág. 29.

- MARCHAN, Simon, “Del arte objetual al arte de concepto», Ediciones Akal, págs. 228-229. 
inventos, tiene numerosos padres. Del lado europeo podríamos empezar con «El monje mirando al mar» (1808-1810) de G.D. Friedrich que tiene, tanto en su esencia como en su forma, mucho en común con Rothko; siguiendo con "Le Nynphées" de Monet, también un ejemplo de cuadro que desafía las leyes de la composición y del marco, además, claro, de Turner, Kandinsky, Malevitch, Mondrian, Klee, los cubistas, Picasso, Matisse, los dadaístas, etc.

Del lado americano habría que mencionar la «Escuela del Río Hudson» de paisajistas norteamericanos del siglo xIx, ya que, sin duda, podríamos considerar a Rothko una derivación de la escuela del paisaje. Es interesante también señalar la influencia de los pintores muralistas mejicanos Siqueiros, Orozco, Ribera, que estuvieron en los años treinta en la coste Oeste. También la coincidencia de que todos o casi todos los pintores del movimiento expresionistas abstracto participaron en el Federal Art Project y, finalmente, las influencias recíprocas de Milton Avery, Pollock, Clyfford Still, Gottlieb y Barnett Newman... Podríamos continuar hablando de las secuelas de esta pintura: Stella, Kenneth Noland, E. Kelly, Al Held, Olitsky, L. Poons en EE.UU., el minimal, el grupo francés de "SupportsSurface", etc. De esta manera dejamos atrás la noción de la historia del arte contemporáneo como una historia de fórmulas más o menos exitosas para encontrarnos con una búsqueda continuada de los hombres para expresarse y hacerse universalmente inteligibles por medio de imágenes.

Finalmente, para aquellos que crean que hablar de Rothko como el inventor de la televisión en color es una broma, les recomiendo que busquen en su enciclopedia la fecha y lugar en que se empieza a emitir y verán como es en EE.UU. y que surge a la par que los grandes lienzos de Rothko. Si se desea obviar la evidencia y pensar en un desdoblamiento de personalidad o inclusive en dos personas distintas, es asunto de «creabilidad" personal. Lo que en todo caso nuestra investigación no puede demostrar es que los dos inventores fueran amantes. 